\title{
Liriomyza Leafminer (Diptera: Agromyzidae) Parasitoid Complex in Different Agroecological Zones, Seasons, and Host Plants in Kenya
}

\author{
C. N. Foba, ${ }^{1,2}$ D. Salifu, ${ }^{1}$ Z. O. Lagat, ${ }^{2}$ L. M. Gitonga, ${ }^{2,3}$ K. S. Akutse, ${ }^{1}$ and \\ K. K. M. Fiaboe ${ }^{1,4}$
}

${ }^{1}$ International Centre of Insect Physiology and Ecology (ICIPE), Plant Health Division, P.0. Box 30772-00100, Nairobi, Kenya (cfoba@icipe.org, dsalifu@icipe.org), ${ }^{2}$ Jomo Kenyatta University of Agriculture and Technology (JKUAT), Department of Zoology, P.0 Box 62000-00200, Nairobi, Kenya (zbisieri@yahoo.com, linusmgitonga@yahoo.co.uk), ${ }^{3}$ Karatina University (KarU), Administration Department, P.O. Box 1957-10101, Karatina, Kenya, ${ }^{4}$ Corresponding author, e-mail: kfiaboe@icipe.org

Received 8 May 2015; Accepted 4 December 2015

\begin{abstract}
Liriomyza leafminers (Diptera: Agromyzidae) are severe pests of vegetables and ornamentals worldwide. Previous studies revealed low leafminer parasitism across different agroecological zones in Kenya. The present paper reports on the composition of leafminer parasitoids at different elevations, in different seasons, and on different host crops. Surveys were conducted monthly from January to November 2012, and nine parasitoid species were recovered. Total mean parasitism in the study sites was $31.23 \pm 1.03 \%$ from a total of 20 different vegetable Liriomyza-infested crops belonging to seven families. Diglyphus isaea (Walker) (Hymenoptera: Eulophidae), Phaedrotoma scabriventris, a newly released parasitoid, and Opius dissitus Muesebeck (Hymenoptera: Braconidae) were the most abundant at all elevations, accounting for $67.3,18.6$, and $9.2 \%$ of total parasitoids, respectively. Elevation, season, and host crop significantly affected the parasitoid species present and their abundance. Diglyphus isaea was more abundant at the high- and mid-elevations at all seasons compared with the low-elevation, whereas the lower-elevation favored higher abundance of $P$. scabriventris and $O$. dissitus during the long rainy season compared with the high- and mid-elevations at all seasons. Of all the host crops surveyed, parasitoids were more abundant on tomato, local kidney bean, snow pea and French bean than other crops. The total parasitism rate observed in this study suggests a considerable improvement in leafminer parasitism compared with previous surveys in Kenya. The implications of these findings for leafminer management in vegetable and ornamental production in Kenya are discussed.
\end{abstract}

Key words: species composition, elevation, parasitism rate, establishment

Liriomyza leafmining flies (Diptera: Agromyzidae) are invasive pests from South America and are among the most important pests of numerous field crops, ornamentals, and vegetables worldwide (Spencer 1985, Parrella 1987, Murphy and LaSalle 1999). In Kenya, three species, Liriomyza huidobrensis (Blanchard), Liriomyza sativae Blanchard, and Liriomyza trifolii (Burgess), account for over $90 \%$ of all Liriomyza species collected from a variety of infested host crops in both cultivated and wild habitats at different elevations of vegetable production (Spencer 1985, KEPHIS 2007, Chabi-Olaye et al. 2008, Foba et al. 2015a). Depending on the plant type, the leafminers' developmental stage, cropping season, and elevation, the pest infestation ranges between 35.7 and $71.7 \%$, with yield losses ranging between 10 and $100 \%$ in Kenya (Chabi-Olaye et al. 2008, Foba et al. 2015a).

Control of leafminers in Kenya has mainly relied on application of synthetic insecticides such as dimethoate, abamectin, imidacloprid, alphacypermethrin, and betacyfluthrin (Gitonga et al. 2010). However, these insecticides do not kill the most destructive larval phase, which is embedded within the leaf epidermis. Studies in Kenya observed that none of the above insecticides used in pea production fields could kill the larval stage of L. huidobrensis at recommended doses, but caused mortality of parasitoids at concentrations below the recommended dose (Gitonga et al. 2010, Guantai et al. 2015). The quarantine status of leafminers and the introduction of maximum residue levels forced Kenyan farmers to seek for alternative management strategies to produce products suitable for export to European Union markets.

In both their native and invaded areas, leafminer populations are regulated by a complex of parasitoid species (Waterhouse and Norris 1987, Johnson 1993, Murphy and LaSalle 1999, Rauf et al. 2000, Mujica and Kroschel 2011). Noyes (2003) listed over 300 species of leafminer fly parasitoids, and over 80 species that attack 
various Liriomyza species. In the Neotropics, Salvo and Valladares (1998) identified 69 parasitoid species of Agromyzidae leafminers in natural, urban, and agricultural habitats of Central Argentina. The Peruvian coast also hosts a very rich parasitoid community of about 63 species (Mujica and Kroschel 2011). These parasitoids species complexes of parasitoid species exhibit a wide range of adaptation to different elevations, host crops, and Liriomyza species, and in their ability to regulate the pest populations below economic thresholds (Waterhouse and Norris 1987, Murphy and LaSalle 1999, Mujica and Kroschel 2011). However, in Kenya, the diversity of parasitoids associated with Liriomyza species is low in all horticultural production systems. Common species include Opius dissitus Muesebeck (Hymenoptera: Braconidae), Diglyphus isaea (Walker) (Hymenoptera: Eulophidae), Neochrysocharis formosa (Westwood) (Hymenoptera: Eulophidae), and Hemiptarsenus varicornis (Girault) (Hymenoptera: Eulophidae), but total parasitism rates are $<6 \%$ (Chabi-Olaye et al. 2008, Guantai et al. 2015). This low parasitoid diversity coupled with low parasitism rates necessitate the introduction of specific neotropical parasitoids against these invasive pests as part of the integrated pest management program.

To enhance biological control of the invasive Liriomyza species in Kenya, the International Centre of Insect Physiology and Ecology (ICIPE), Nairobi, Kenya, in partnership with the International Potato Center (CIP), Peru, South America, and Kenya Agricultural Research Institute (KARI), imported three endoparasitoids, Halticoptera arduine (Walker) (Hymenoptera: Pteromalidae), Chrysocharis flacilla (Walker) (Hymenoptera: Eulophidae), and Phaedrotoma scabriventris Nixon (Hymenoptera: Braconidae), from Peru in December 2008. Of these parasitoids, P. scabriventris was the first to successfully establish in the quarantine facilities of ICIPE. The parasitoid also coexisted with major indigenous parasitoids present in Kenya in laboratory experiments (Akutse et al. 2015, Foba et al. 2015b) and was released in the study sites at the beginning of the present study. In its native areas, namely, Peru, Chili, Brazil, and Argentina, P. scabriventris accounts for over $50 \%$ of total parasitism of Liriomyza species, especially on the most aggressive species L. huidobrensis, which infests a wide range of host crops in different agroecological zones $(<500$ to $>4,000 \mathrm{~m}$ a.s.l. and temperature: 4-24 ${ }^{\circ} \mathrm{C}$; Serantes de González 1974, Valladares and Salvo 2001, Videla et al. 2006, Valencia 2008). Although P. scabriventris has a wide geographical distribution, its performance is highest at higher elevation (3,250 $\mathrm{m}$ a.s.l.), especially on L. huidobrensis in Peru (Salvo 1996, Mujica and Cisneros 1997, Valladares and Salvo 2001, Salvo et al. 2005). Based on this, we expect a similar trend in Kenya.

The occurrence and relative abundance of the most invasive leafminers identified in Kenya are influenced by season, host crops, and elevations (Spencer 1989, Murphy and LaSalle 1999, Rauf et al. 2000, Weintraub 2001, Andersen et al. 2002, Johansen et al. 2003, Chabi-Olaye et al. 2008, Tantowijoyo and Hoffmann 2010, Mujica and Kroschel 2011, Foba et al. 2015a). These leafminers have continued to depict high adaptability with complex histories of invasion and establishing in many countries worldwide, exhibiting interspecific interactions, and causing damage to a wide range of crops and ornamentals at different agroecological zones (Chaney 1995, Kang 1996, Costa-Lima et al. 2010, Yıldırım and Ünay 2011, Gao et al. 2011). As variation in climatic conditions is related to the elevation gradient at different agroecological zones, and species richness and the structure of species assemblages differ at different elevations (Brehm et al. 2003, McCain 2005, Kessler et al. 2011), understanding how parasitoid species respond to gradient and vegetation at different agroecological zones may be useful in pest management
(Malhi et al. 2010). The present study was conducted to determine the effect of agroecological zones, production seasons, and host crops on the leafminer parasitoid complex in Kenya.

\section{Materials and Methods}

\section{Study Sites}

Three agroecological zones based on elevation, namely, highelevation, $>1,800$ m. a.s.l (Nyeri County, Central Kenya); mid-elevation, 1,000 to 1,800 m. a.s.l (Kajiado County, Rift Valley Region); and low-elevation, $<1000 \mathrm{~m}$. a.s.l (Makueni County, Eastern Region), were selected for the study. In each agroecological zone, three locations with intensive vegetable production, reliable irrigation schemes, and highly infested fields of about $70 \%$ infestation on leaves were selected for the study. The three agroecological zones were located at least $65 \mathrm{~km}$ apart and locations within the zones were approximately $5 \mathrm{~km}$ apart.

In the high-elevation, surveys were conducted at three locations: Sagana ( $0^{\circ} 21^{\prime} 9.972^{\prime \prime}$ S, $\left.37^{\circ} 5^{\prime} 13.632^{\prime \prime} \mathrm{E}\right)$, Kabaru $\left(0^{\circ} 17^{\prime} 48.408^{\prime \prime} \mathrm{S}\right.$, $\left.37^{\circ} 6^{\prime} 28.116^{\prime \prime} \mathrm{E}\right)$, and Naromoru ( $0^{\circ} 11^{\prime} 9.312^{\prime \prime} \mathrm{S}, 37^{\circ} 6^{\prime} 36.972^{\prime \prime} \mathrm{E}$; Fig. 1). The mean range of temperature (minimum and maximum) is 8 to $24^{\circ} \mathrm{C}$, and mean rainfall is from 1,500 to $2,000 \mathrm{~mm}$ per annum. Local farmers grow a variety of vegetables, with peas (Pisum sativum L.), French bean (Phaseolus vulgaris L.), and potato (Solanum tuberosum L.) being the most common leafminer hosts (Foba et al. 2015a).

In the mid-elevation, survey locations were Namelok $\left(2^{\circ}\right.$ $43^{\prime} 6.096^{\prime \prime}$ S, $37^{\circ} 27^{\prime} 39.06^{\prime \prime}$ E), Empiron ( $2^{\circ} 50^{\prime} 57.948^{\prime \prime}$ S, $37^{\circ}$ $\left.32^{\prime} 15.144^{\prime \prime} \mathrm{E}\right)$, and Inkisanjani $\left(2^{\circ} 53^{\prime} 56.4^{\prime \prime} \mathrm{S}, 37^{\circ} 34^{\prime} 51.564^{\prime \prime} \mathrm{E}\right)$ in Kajiado County (Fig. 1). The mean range of temperature is 16 to $26^{\circ} \mathrm{C}$, and mean rainfall varies from 450 to $1,200 \mathrm{~mm}$ per annum. The main leafminer hosts grown are different varieties of local kidney bean, French bean, and tomato (Lycospersicon esculentum Miller; Foba et al. 2015a).

In the low-elevation, survey locations were Kwakyai $\left(2^{\circ}\right.$ $23^{\prime} 6.612^{\prime \prime}$ S, $38^{\circ} 0^{\prime} 9.504^{\prime \prime}$ E), Kikoo ( $2^{\circ} 23^{\prime} 50.928^{\prime \prime}$ S, $37^{\circ}$ $\left.59^{\prime} 8.052^{\prime \prime} \mathrm{E}\right)$, and Mangelete ( $\left.2^{\circ} 41^{\prime} 57.552^{\prime \prime} \mathrm{S}, 38^{\circ} 7^{\prime} 32.268^{\prime \prime} \mathrm{E}\right)$ in Makueni County (Fig. 1). The mean range of temperature is 21 to $31^{\circ} \mathrm{C}$, and mean rainfall ranges from 800 to $1,200 \mathrm{~mm}$ per annum. The main leafminer hosts grown are local kidney bean and the tomato (Foba et al. 2015a).

Generally, most agricultural crop production areas in Kenya are characterized by four cropping seasons, namely, the long rains, the short rains, the cold dry, and the hot dry seasons, which differ depending on elevation and the cropping seasons and have been inconsistent especially at the mid- and low-elevations since 1980s (Hassan 1998, Jaetzold et al. 2006). The crops grown differ at different elevations; the high-elevation crops are mainly for exports, whereas the mid- and low-elevation crops are for local market. The agroecological zones under study are ones in which $P$. scabriventris was released into Kenya from a laboratory culture of CIP in Peru, South America, in December 2008.

\section{Leafminer Parasitoid Diversity and Abundance \\ Field Surveys and Sampling Methods}

Field surveys were carried out monthly from January 2012 to November 2012 to determine the species complex of leafminer parasitoids on vegetable crops in the three locations across each elevation of vegetable production in Kenya.

During each observation date, the sampling area in each field visited was subdivided into four equal quadrants and from each 


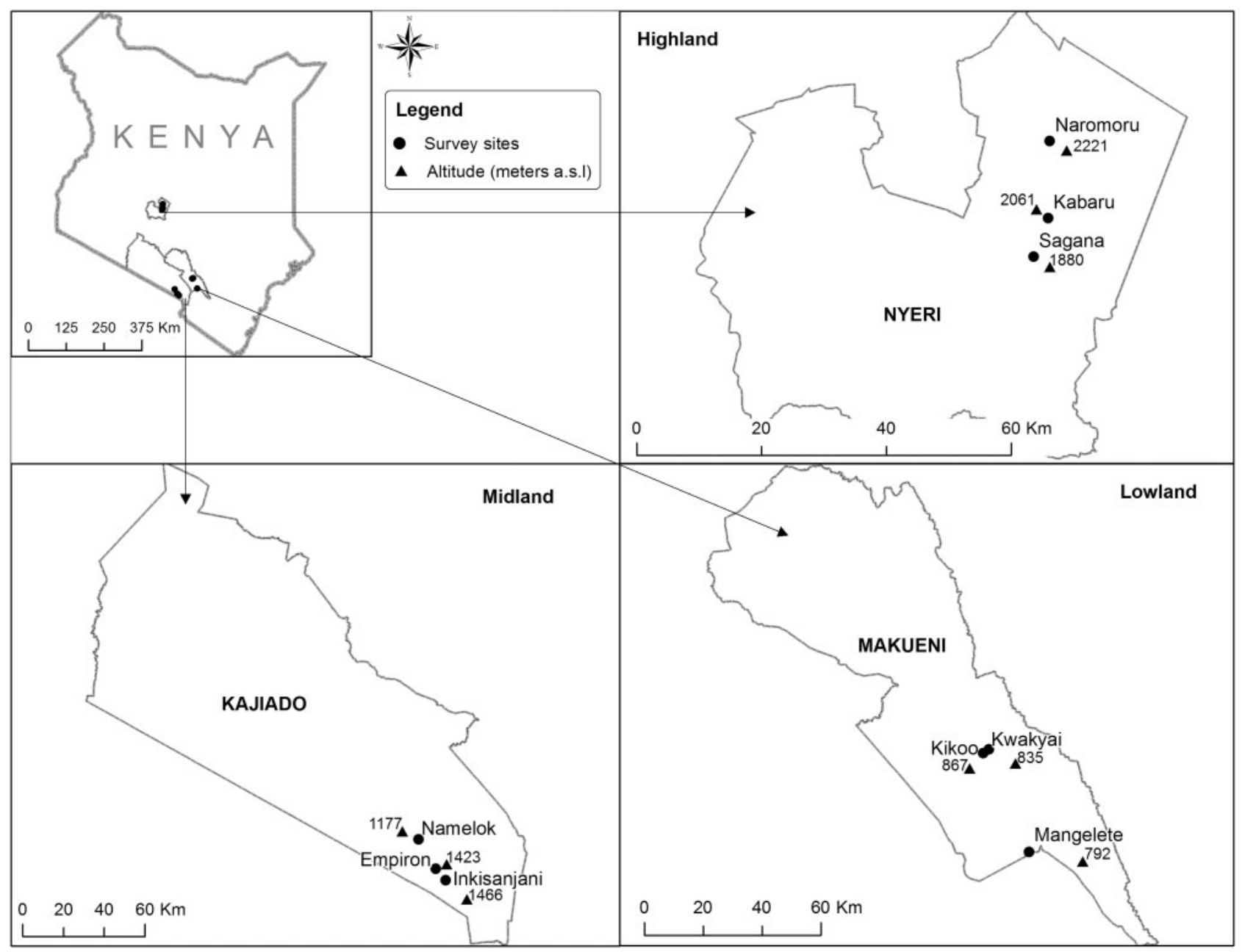

Fig. 1. Study sites in high-, mid-, and low-elevations of Kenya.

quadrant, a maximum of 25 infested leaves with developing or developed mines containing leafminer larvae ("live mines") were sampled, giving a maximum of 100 leaves in total per field for laboratory incubation and observation. The sampled infested leaves were immediately preserved in perforated plastic paper bags and afterwards transferred onto damp paper towels and then placed in plastic rearing containers ( 19 by 13 by $8 \mathrm{~cm}$ ). The rearing containers were closed with lid containing fine netting muslin windows ( 16 by $9.5 \mathrm{~cm}$ ) for ventilation and were placed in cooler box to prevent overheating before transportation to the laboratory. Pupae were collected from the rearing containers using soft camel hair brushes as they formed, counted, and incubated in labeled plastic petri dishes until adults of leafminer flies or parasitoids emerged. Laboratory conditions were maintained at $25 \pm 2{ }^{\circ} \mathrm{C}$ and $80 \pm 5 \% \mathrm{RH}$. Adult parasitoids were preserved in $80 \%$ ethanol amended with $10 \%$ glycerin, and identification was done using conventional taxonomic keys and identification keys from the Liriomyza leafminers project at ICIPE, Duduville campus, Nairobi, Kenya. The adult parasitoids were further sent to the Royal Museum of Central Africa, Belgium, for confirmation. Voucher specimens of identified adult parasitoid species were stored in the entomological museum at ICIPE, Duduville campus, Nairobi, Kenya. Field surveys were conducted at a radius of about $4.5 \mathrm{~km}$ around $P$. scabriventris release sites at each elevation. A maximum of 10 farmers' crop fields were surveyed from each location during each observation date. Variables such as type of host crop, stage of crop, and type of insecticide sprayed were also recorded during each sampling period.

\section{Data Analyses}

The parasitism rates were expressed as proportion of emerged adult parasitoids out of all insects (i.e., emerged adult parasitoids and leafminer flies). Canonical correspondence analysis (CCA), a multivariate ordination method, was used to examine the amount of variation in the parasitoid species composition data accounted for by the explanatory variables, in this case the environmental factors, namely, elevation and season, and the random factor, host crop (Muylaert et al. 2000, Pires-Venin 2001). Abundance data collected on Halticoptera, Opiinae, and Figitidae species were excluded from the analysis because the three together accounted for $<1 \%$ of all the parasitoids recorded in the study. The species abundance matrix was log-transformed before CCA to reduce variability and the effect of outliers. To determine the variation accounted for by each factor, CCA was performed on the entire species composition matrix constrained by each individual factor, respectively. As the crops grown at each elevation and season were different, CCA constrained by elevation and season, conditional on host crop, was performed to determine the "unbiased effect" of season and elevation on the parasitoid species matrix variation. In return, to examine the effect of host crop on parasitoid species matrix variation, CCA 
constrained by host crop conditional on season and elevation was performed. The significance of the environmental variables was tested by means of Monte Carlo permutation tests (999 unrestricted permutations). The CCA was implemented in $\mathrm{R}$ version 3.2.1 ( $\mathrm{R}$ Development Core Team, 2015) using vegan package (Oksanen et al. 2015). The monthly parasitism rates for each species were analyzed using a generalized linear mixed model (GLMM) with random intercept and slope to examine the effect of elevation. GLMM produces analysis of deviance with Wald $\chi^{2}$ as a test statistic for the terms in the model. The GLMM was implemented in $\mathrm{R}$ version 3.2.1using the lmer function of the lme4 package (Bates et al. 2012). Observed parasitism rates at each elevation were further compared using an adjusted Tukey's test in R.

\section{Results}

\section{Leafminer Parasitoids Species Composition}

In total, 9,282 hymenopterans composed of nine leafminer parasitoid species were recorded from Liriomyza leafminer-infested leaves collected from farmer fields. The nine species belong to the families Eulophidae (D. isaea, N. Formosa, Meruacesa sp. Walker, and $H$. varicornis), Braconidae (O. dissitus, $P$. scabriventris, and an unidentified Opiinae species), Pteromalidae (Halticoptera sp.), and an unidentified species in the family Figitidae. Out of the total parasitoids, 3,942 $(42.5 \%)$ were recorded in the high-elevation, 2,383 $(25.7 \%)$ in the mid-elevation, and 2,957 $(31.86 \%)$ in the low-elevation. Diglyphus isaea was the most abundant parasitoid species at all elevations: 3,460 (87.8\%), 1,601 (67.2\%), and 1,188 (40.2\%) at high-, mid-, and low-elevations, respectively. Phaedrotoma scabriventris was recovered from all release sites, 101 (5.5\%) at highelevation, $210(19.2 \%)$ at mid-elevation, and 1,054 (35.6\%) at low-elevation. Overall, D. isaea, P. scabriventris, and O. dissitus represented $95.2 \%$ of all parasitoids identified in the study. Variation partitioning using CCA showed a clear indication that host crop had a significant effect $(11 \%$ of variation in species matrix) on the parasitoid species abundance $(P=0.001$; Table 1$)$, providing justification for use as a covariable. The environmental matrix (which contained three variables) explained a total of $15.4 \%$ of variation in the parasitoid species matrix (Table 1). CCA model constrained by season and elevation conditional on host crop was statistically significant, $P=0.001$ (Table 1 ). The results of this CCA model, Season +Elevation + Condition (host crop), are plotted in Fig. 2. Axis 1 explains $59.9 \%$ of the constrained variation in the species data. This axis is strongly determined by elevation. The positive side of Axis 1 distinguishes the species present predominantly in the low-elevation, namely, O. dissitus and P. scabriventris, and the negative side of Axis 1 distinguishes $D$. isaea that is predominant at mid- and high-elevation. Neochrysocharis formosa is unique in that its abundance was similar in low-, mid-, and high-elevations. Axis 2 explains $25.1 \%$ of the constrained variation in the species data and is determined by seasonality (Fig. 2).

Considering the seasons at each elevation, $D$. isaea was the most abundant parasitoid species during all cropping seasons, followed by $P$. scabriventris, then $O$. dissitus (Table 2). Proportions of D. isaea remained relatively high, exceeding $80 \%$ at high-elevation and exceeding $66 \%$ at mid-elevation throughout all the seasons (Table 2). However, at low-elevation, the proportion of D. isaea was most abundant during the dry cold season $(51.0 \%)$ and least abundant during the short rainy season $(11.6 \%$; Table 2$)$. The proportion of the exotic P. scabriventris was more abundant during the long rainy, dry hot, and short rainy seasons compared with the dry cold season at high-elevation (Table 2). At mid-elevation, P. scabriventris was less abundant during the short rainy season compared with the other seasons, and at low-elevation, it was generally more abundant during all the cropping seasons (Table 2). Opius dissitus

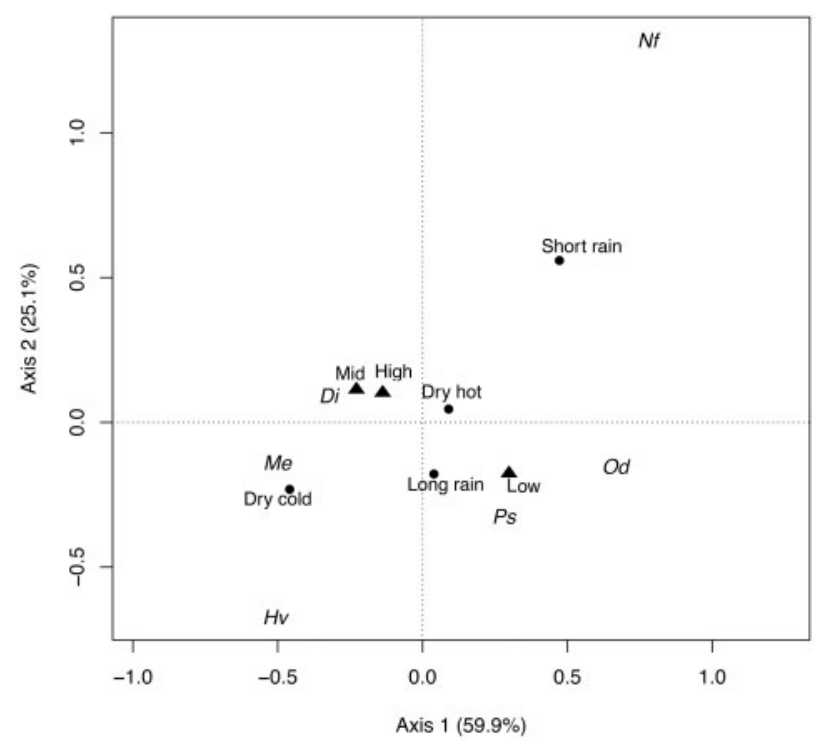

Fig. 2. Plot of CCA results of the parasitoid species ordination constrained by elevation and season with crop grown as covariable. $N f=$ Neochrysocharis formosa, $P s=$ Phaedrotoma scabriventris, Me=Meruacesa $\mathrm{sp}, \mathrm{Od}=$ Opius dissitus, $\mathrm{Di}=$ Diglyphus isaea, $\mathrm{Hv}=$ Hemiptarsenus varicornis, High $=$ highelevation, Mid= mid-elevation, low = low-elevation.

Table 1. CCA results and variation accounted for by environmental factors for the parasitoid species abundance data together with $P$-value of model as evaluated using Monte Carlo permutation test

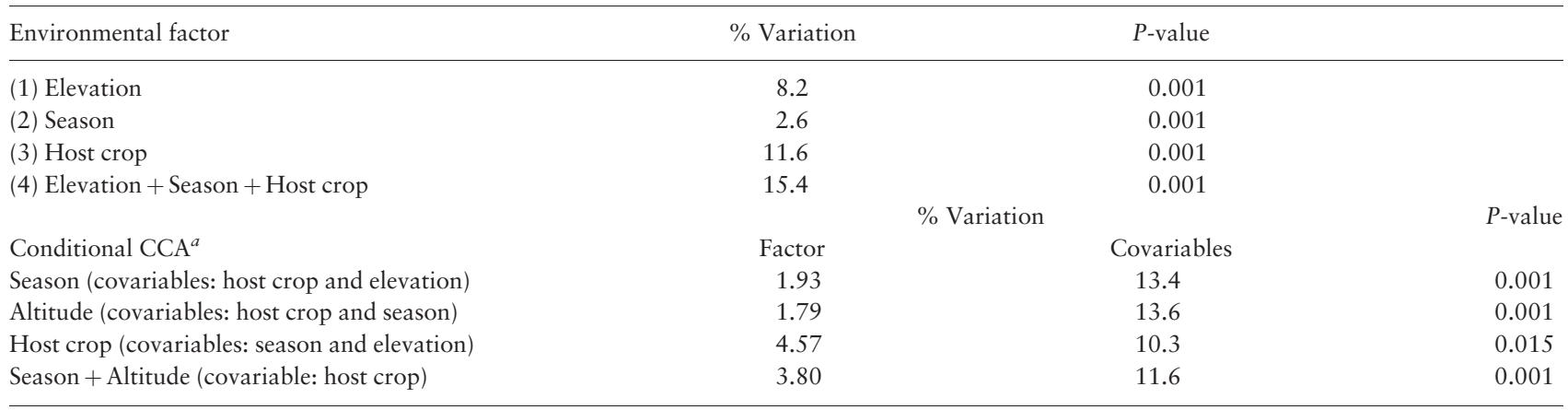

\footnotetext{
${ }^{a}$ CCA on species matrix constrained by the given factor conditional on the covariables indicated.
} 


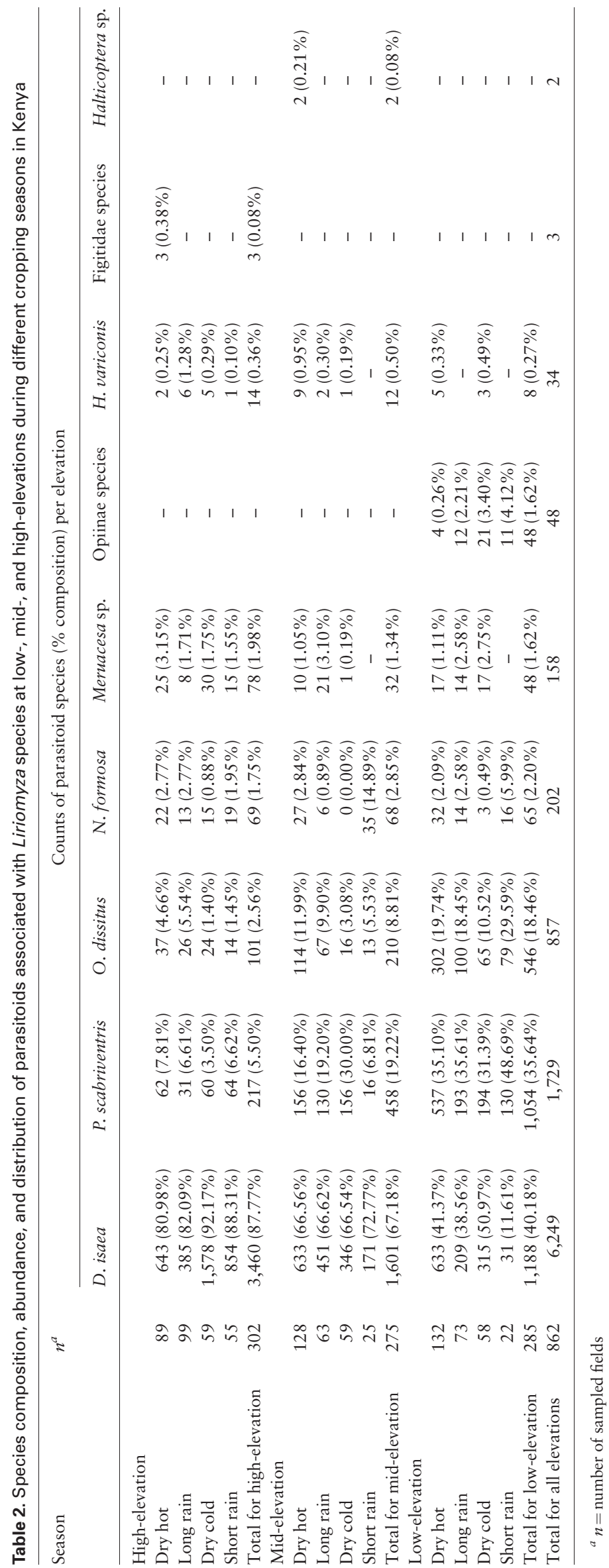


Table 3. Observed parasitism rates (\%) of Liriomyza leafminer flies parasitoid species at low-, mid-, and high-elevations in vegetable production systems in Kenya

\begin{tabular}{|c|c|c|c|c|c|}
\hline \multirow[t]{2}{*}{ Parasitoid species } & \multicolumn{5}{|c|}{ Parasitism rate $(\%$ Mean \pm SE $)$} \\
\hline & High-elevation $\left(n^{a}=302\right)$ & Mid-elevation $(n=275)$ & Low-elevation $(n=285)$ & Wald $\chi^{2}, \mathrm{df}=2$ & $P$-value \\
\hline D. isaea & $21.25 \pm 1.61 \mathrm{a}$ & $20.36 \pm 1.53 a$ & $13.69 \pm 1.24 b$ & 2.60 & 0.01 \\
\hline P. scabriventris & $1.51 \pm 0.33 b$ & $6.36 \pm 0.81 \mathrm{a}$ & $12.33 \pm 1.08 \mathrm{a}$ & 35.40 & $<0.001$ \\
\hline O. dissitus & $1.57 \pm 0.48 b$ & $3.11 \pm 0.49 \mathrm{a}$ & $7.67 \pm 0.89 a$ & 20.90 & $<0.001$ \\
\hline N. formosa & $0.80 \pm 0.24 a$ & $1.13 \pm 0.41 \mathrm{a}$ & $0.88 \pm 0.23 a$ & 0.15 & 0.93 \\
\hline Meruacesa sp. & $0.71 \pm 0.23 \mathrm{a}$ & $0.46 \pm 0.17 \mathrm{a}$ & $0.89 \pm 0.38 \mathrm{a}$ & 0.94 & 0.62 \\
\hline Opiinae species & - & - & $0.38 \pm 0.15$ & - & - \\
\hline H. variconis & $0.19 \pm 0.09 \mathrm{a}$ & $0.43 \pm 0.37 \mathrm{a}$ & $0.26 \pm 0.18 \mathrm{a}$ & 4.50 & 0.11 \\
\hline Figitidae species & $0.02 \pm 0.02$ & - & - & - & \\
\hline Halticoptera sp. & - & $0.01 \pm 0.01$ & - & - & - \\
\hline Total & $26.06 \pm 1.72 \mathrm{a}$ & $31.85 \pm 1.77 a$ & $36.11 \pm 1.82 \mathrm{a}$ & 4.18 & 0.12 \\
\hline
\end{tabular}

${ }^{a} \mathrm{n}=$ number of sampled fields

Means followed by the same letters across elevation areas are not significantly different

was more abundant during the dry hot and long rainy seasons compared with the dry cold and short rainy seasons at both high- and mid-elevations (Table 2). However, at low-elevation, it was most abundant during the short rainy season compared with the other three seasons (Table 2).

On average, an overall parasitism rate of $31.2 \pm 1.03 \%$ was recorded on Liriomyza species across all survey sites, with $26.1 \pm 1.72 \%$ for high-elevation, $31.9 \pm 1.77 \%$ for mid-elevation, and $36.1 \pm 1.82$ for low-elevation (Table 3). There were significant differences in the parasitism rates by $D$. isaea (Wald $\chi^{2}=2.60$, $\mathrm{df}=2, \quad P=0.01$ ), $\quad P . \quad$ scabriventris (Wald $\chi^{2}=35.40, \quad \mathrm{df}=2$, $P<0.001$ ), and O. dissitus (Wald $\chi^{2}=20.90, \mathrm{df}=2, P<0.001$ ) across elevations (Table 3 ). The specific parasitism rate by $D$. isaea was higher at high- and mid-elevations compared with low-elevation (Table 3). The specific parasitism rate by $P$. scabriventris was about 10 times higher in low-elevation compared with high-elevation and two times higher compared with mid-elevation (Table 3). The specific parasitism rate by $O$. dissitus was about five times higher in low-elevation compared with high-elevation and two times higher compared with mid-elevation (Table 3). The contribution of P. scabriventris-specific parasitism to total parasitism was highest at low-elevation sites $(34.14 \%)$ and similar to D. isaea's contribution to total parasitism at low-elevation $(37.91 \%)$ compared with O. dissitus' specific parasitism contribution to total parasitism at the same elevation (21.24\%; Table 3). Phaedrotoma scabriventris's specific parasitism contribution to total parasitism was lowest at highelevation $(5.8 \%)$. Specific parasitism rate by $P$. scabriventris increased from $<10 \%$ during the long rainy and dry cold seasons to $24.15 \%$ during the short rainy season of monitoring in low-elevation. However, no clear pattern was observed for specific parasitism of the other parasitoids across seasons.

All parasitoids identified were collected on Liriomyza species infesting a total of 20 different vegetable host crops belonging to seven families: Fabaceae (French bean and local kidney bean; Phaseolus vulgaris L., garden pea, snow pea, and sugar snap; Pisum sativum L., cowpea; Vigna unguiculata (L.) Walp, dolichos bean; Lablab purpureus (L.) Sweet), Solanaceae (potato; Solanum tuberosum L., tomato; Solanum lycopersicum L., sweet pepper; Capsicum L., brinjale eggplant; Solanum melongena L.), Cucurbitaceae (watermelon; Citrullus lanatus (Thunb.) Matsun and Nakai, pumpkin; Cucurbita maxima Duchesne, butternut squash; Cucurbita moschata Duchesne ex Poir, bitter gourd; Momordica charantia L., courgette; Cucurbita pepo L.), Malvaceae (okra; Abelmoschus esculentus (L.) Moench),
Brassicaceae (kale; Brassica oleracea acephala L.), Amaranthaceae (spinach; Spinacia oleracea L.), and Amaryllidaceae (onion; Allium cepa L.) from the three elevations (Table 4). Parasitoid abundance was highest on the Fabaceae at high- and mid-elevations and on the Solanaceae at low-elevation (Table 4).

Diglyphus isaea was recovered from all Liriomyza-infested host crops surveyed, with the exception of onion surveyed at the midelevation (Table 4). This parasitoid was also the most abundant on all the host crops surveyed (Table 4). The host crop range for the exotic $P$. scabriventris and its closest allied $O$. dissitus were almost similar and also high, i.e., 18 crops each (Table 4). While no P. scabriventris was collected on butternut squash, O. dissitus was not collected on leafminer infesting bitter gourd leaves at low-elevation, and, like D. isaea, both parasitoid species were not collected on leafminer infesting onion leaves surveyed at mid-elevation (Table 4). Among all the crops surveyed, French bean and local kidney bean yielded the highest proportions of $P$. scabriventris and $O$. dissitus, while snow pea and tomato yielded the highest $D$. isaea proportion (Table 4).

Although the total parasitoid abundance on snow pea was highest, the percentage parasitism $(21.76 \pm 2.48 \%)$ was lower than on two other crops: French bean $(55.25 \pm 4.99 \%)$ and local kidney bean $(39.79 \pm 6.17 \%)$. In addition, snow pea was found only at high-elevation. At the mid-elevation, tomato, local kidney bean, and French bean-infested leaves yielded the highest total parasitism: $25.98 \pm 2.26 \%$ on tomato, $37.44 \pm 4.31$ on local kidney bean, and $37.33 \pm 3.59 \%$ on French bean. Although tomato, the most frequently survey crop at low-elevation, yielded the highest parasitoid abundance, total parasitism on it was not the highest: $28.80 \pm 2.11 \%$, compared with $53.93 \pm 4.15 \%$ on local kidney bean, which was about half of the number of surveyed fields for tomato.

\section{Discussion}

Nine leafminer parasitoid species, including the exotic P. scabriventris, were recorded in this study with over $30 \%$ average total parasitism. These results suggest improvement in leafminer parasitism in Kenya, as previous parasitism was less than $6 \%$ (Chabi-Olaye et al. 2008). The diversity of leafminer parasitoids in Kenya in this study is also higher (i.e., nine species) compared with Chabi-Olaye et al. (2008), who reported only four parasitoid species (O. dissitus, D. isaea, N. formosa, and H. varicornis). In addition, the Meruacesa 
Table 4. Proportion (\%) of parasitoid species abundance associated with Liriomyza infested crops at high-, mid-, and low-elevations in vegetable production systems in Kenya

\begin{tabular}{|c|c|c|c|c|c|c|c|c|c|c|}
\hline \multicolumn{11}{|c|}{ Parasitoid species composition and abundance $(\%)$ per elevation } \\
\hline $\begin{array}{l}\text { Crop common } \\
\text { name }\end{array}$ & $n^{a}$ & $\begin{array}{c}D . \\
\text { isaea }\end{array}$ & $\begin{array}{c}P . \\
\text { scabriventris }\end{array}$ & $\begin{array}{c}\text { O. } \\
\text { dissitus }\end{array}$ & $\begin{array}{c}N . \\
\text { formosa }\end{array}$ & $\begin{array}{c}\text { Meruacesa } \\
\text { sp. }\end{array}$ & $\begin{array}{l}\text { Opiinae } \\
\text { species }\end{array}$ & $\begin{array}{c}H . \\
\text { variconis }\end{array}$ & $\begin{array}{l}\text { Figitidae } \\
\text { species }\end{array}$ & $\begin{array}{c}\text { Halticoptera } \\
\text { sp. }\end{array}$ \\
\hline \multicolumn{11}{|l|}{ High-elevation } \\
\hline Spinach & 1 & 0.48 & 0.03 & 0.08 & - & - & - & - & - & - \\
\hline Courgette & 9 & 3.25 & 0.13 & 0.03 & 0.05 & 0.08 & - & - & - & - \\
\hline French bean & 46 & 19.48 & 1.98 & 0.71 & 0.43 & 0.30 & - & 0.13 & - & - \\
\hline Garden pea & 15 & 2.79 & 0.18 & 0.05 & 0.05 & 0.20 & - & 0.03 & - & - \\
\hline Local kidney bean & 26 & 4.16 & 1.52 & 0.30 & 0.23 & 0.30 & - & - & - & - \\
\hline Snow pea & 107 & 36.20 & 0.63 & 0.20 & 0.56 & 0.68 & - & 0.18 & - & - \\
\hline Sugar snap & 22 & 12.58 & 0.18 & 0.13 & 0.23 & 0.28 & - & - & - & - \\
\hline Potato & 65 & 5.18 & 0.74 & 1.01 & 0.20 & 0.10 & - & 0.03 & 0.08 & - \\
\hline Sweet pepper & 4 & 0.99 & - & - & - & - & - & - & - & - \\
\hline Tomato & 7 & 2.66 & 0.13 & 0.05 & - & 0.03 & - & - & - & - \\
\hline \multicolumn{11}{|l|}{ Mid-elevation } \\
\hline Onion & 1 & - & - & - & - & 0.04 & - & - & - & - \\
\hline Courgette & 1 & 0.13 & - & 0.13 & - & - & - & - & - & - \\
\hline Watermelon & 3 & 0.92 & 0.63 & - & - & - & - & - & - & - \\
\hline Cowpea & 1 & 0.13 & 0.08 & 0.04 & - & - & - & - & - & - \\
\hline French bean & 78 & 22.66 & 3.78 & 1.43 & 1.47 & 0.21 & - & 0.04 & - & - \\
\hline Garden pea & 1 & 0.13 & - & - & - & - & - & - & - & - \\
\hline Local kidney bean & 57 & 10.95 & 5.54 & 2.69 & 0.29 & 0.34 & - & 0.04 & - & - \\
\hline Okra & 1 & 0.71 & 0.04 & - & - & - & - & - & - & - \\
\hline Potato & 4 & 0.34 & 0.13 & - & - & - & - & 0.04 & - & - \\
\hline Tomato & 128 & 31.22 & 9.02 & 4.53 & 1.09 & 0.76 & - & 0.38 & - & 0.08 \\
\hline \multicolumn{11}{|l|}{ Low-elevation } \\
\hline Kale & 4 & 0.27 & 0.07 & 0.07 & - & - & - & - & - & - \\
\hline Bitter gourd & 1 & 0.37 & 0.20 & - & - & - & - & - & - & - \\
\hline Butternut squash & 1 & 0.47 & - & 0.03 & - & - & - & - & - & - \\
\hline Pumpkin & 4 & 0.17 & 0.07 & 0.17 & 0.03 & 0.07 & - & - & - & - \\
\hline Watermelon & 13 & 1.22 & 1.86 & 1.05 & - & 0.03 & - & - & - & - \\
\hline Cowpea & 11 & 0.61 & 1.15 & 0.91 & 0.07 & - & - & 0.03 & - & - \\
\hline Dolichos bean & 1 & 0.10 & 0.30 & 0.44 & - & 0.03 & - & - & - & - \\
\hline Local kidney bean & 65 & 5.82 & 11.73 & 6.02 & 0.27 & 0.20 & 0.07 & 0.03 & - & - \\
\hline Okra & 24 & 2.60 & 2.10 & 1.15 & 0.10 & 0.17 & 0.03 & - & - & - \\
\hline Brinjale eggplant & 1 & 0.20 & 0.07 & 0.03 & - & 0.10 & - & 0.03 & - & - \\
\hline Sweet pepper & 3 & 0.27 & 0.07 & 0.03 & - & - & - & - & - & - \\
\hline Tomato & 157 & 28.07 & 18.03 & 8.56 & 1.72 & 1.01 & 1.52 & 0.17 & - & - \\
\hline
\end{tabular}

${ }^{a} \mathrm{n}=$ number of sampled fields

Percentages are calculated from total parasitoid counts per elevation; high-elevation (3,942), mid-elevation $(2,383)$, and low-elevation $(2,957)$

sp. found during the survey is new to science (A. Gumovski, personal communication), and further description is being carried out by the Royal Museum of Central Africa in Belgium for its publication as a new species. The high leafminer parasitism observed in this study may be owing to considerable farmer awareness campaigns on conservation of parasitoids rolled out prior to release of P. scabriventris. Parasitism rates reported herein may represent minimum estimates of parasitism, because they are based only on numbers of emerged adult parasitoids and does not account for host killing effects. However, nonreproductive mortality is important only in leafminer ectoparasitoids like D. isaea (Liu et al. 2013, Akutse et al. 2015) and is negligible in endoparasitoids (Foba et al. 2015 , our unpublished data). Generally, elevation played a significant role in parasitoid presence and their abundance. Differences in elevation are associated with environmental changes that affect ecological parasitoid communities (Brehm et al. 2003, McCain 2005, Malhi et al. 2010, Kessler et al. 2011). An important factor is differences in the occurrence and relative abundance of leafminers, which affects the presence and abundance of parasitoid populations
(Spencer 1989, Murphy and LaSalle 1999, Rauf et al. 2000, Weintraub 2001, Andersen et al. 2002, Johansen et al. 2003, ChabiOlaye et al. 2008, Tantowijoyo and Hoffmann 2010, Mujica and Kroschel 2011, Foba et al. 2015a).

The indigenous ectoparasitoid $D$. isaea was the most abundant species and accounted for the highest leafminer parasitism at all elevations. This dominance of $D$. isaea at all elevations is a new finding in Kenya, as previous studies indicated that $O$. dissitus was the most dominant parasitoid species of leafminers (Chabi-Olaye et al. 2008). However, Chabi-Olaye et al. (2008) carried out a one-time countrywide survey spread over different seasons without repeated sampling in the same sites over seasons, whereas in the present study, samples were collected in same sites monthly, and hence, capturing variation in seasons. Furthermore, in the present study, D. isaea was more abundant at high-elevation, followed by mid-elevation, and then low-elevation, and parasitism rates followed the same trend. The fact that $D$. isaea was the most abundant at the high-elevation contradicts the normal expectation based on its biological information in literature. For instance, Cheah (1987), Minkenberg (1989), Van 
Der Linden (2004), and Haghani et al. (2007) reported that cooler temperatures observed at high-elevation in Kenya hamper its reproduction and development. Thus, our findings suggest that D. isaea may be adapting to colder areas and can perform at all elevations. Another possible reason for the higher abundance of $D$. isaea at high-elevations could be the effect of leafminer abundance on the parasitoid. Indeed, Foba et al. (2015) reported under the same conditions that leafminer populations were two to three times more abundant at high-elevation than mid- and low-elevations, respectively. Furthermore, host crop could have also led to such a higher abundance of $D$. isaea at high-elevation. The parasitoid was more abundant on snow pea, which was, however, recorded only at highelevation. We hypothesize therefore that temperature, leafminer abundance, and host crop preference may have contributed individually or combined to the higher abundance of $D$. isaea at highelevation. Diglyphus isaea is a worldwide primary ectoparasitoid of numerous Liriomyza leafminers native to Europe (Weintraub and Horowitz 1995, Noyes 2003, Bazzocchi et al. 2003, Malais and Ravensberg 2003, van Der Linden 2004, Tran et al. 2006, ChabiOlaye et al. 2008, Akutse et al. 2015). This species has been commercialized as a biological control agent against leafminers (Musundire et al. 2011). Diglyphus isaea is known to cause death of host larvae, not only by reproductive host-killing through parasitization, but also by nonreproductive host-killing through host-feeding and/or stinging without feeding and oviposition (Liu et al. 2013, Akutse et al. 2015). Thus, the total mortality of leafminers observed in this study could be higher, as nonreproductive host killing was not evaluated.

The exotic endoparasitoid $P$. scabriventris was recovered from all release sites and was the second highest in abundance of all parasitoids identified on leafminers. The highest parasitism rate was recorded at low-elevation compared with mid- and high-elevations. The fact that $P$. scabriventris reached the top two in terms of parasitoid abundance within the first year after its release confirms reports from its original zone. For example, this parasitoid is often the dominant parasitoid of L. huidobrensis in Argentina, Brazil, Chile, and Peru, South America, where it represents up to $50 \%$ of total parasitism (Serantes de González 1974, Salvo and Valladares 1995). In addition to its successful establishment, the parasitoid could complement the two most important local parasitoid species reported in East Africa: D. isaea and O. dissitus. With regard to $D$. isaea, there is a territory difference, with $D$. isaea being more abundant at high-elevation, whereas $P$. scabriventris was more abundant at lower elevations. In regard to O. dissitus, while both species share the same elevation preference, the seasonal differences in their abundance would enable a year-round parasitism as compared with each of them used alone. This is promising for future improvement of biological control of leafminers in Kenya and East Africa. However, follow-up surveys will be required to assess performance, as its specific parasitism in the first year post-release was low.

In Kenya, $P$. scabriventris was more abundant and had higher parasitism at lower elevations. This contrasts with previous reports from its original range. For example, although $P$. scabriventris has a wide geographical distribution, its performance has been highest at higher elevation $(3,250 \mathrm{~m}$ a.s.l.), especially on L. huidobrensis in Peru, where the Kenyan population was imported (Salvo 1996, Mujica and Cisneros 1997, Valladares and Salvo 2001, Salvo et al. 2005). Given that $P$. scabriventris was recovered from all elevations studied in Kenya, we expect the same performance in other countries within similar ranges of elevation and temperature, as reported by Salvo (1996) in Argentina and Mujica and Cisneros (1997) in Peru. However, under laboratory conditions, Mujica et al. (2009) reported best performance of $P$. scabriventris between 15 and $20^{\circ} \mathrm{C}$, with a significant decrease in progeny at temperatures above $20^{\circ} \mathrm{C}$. Valladares and Salvo (2001) reported higher performance of $P$. scabriventris under cooler winter and fall conditions at temperatures below $15{ }^{\circ} \mathrm{C}$ in Argentina. It was therefore expected that this parasitoid would perform better in higher elevations in Kenya. Instead, it was more abundant at lower elevations. Furthermore, according to Foba et al. (2015), leafminers are more abundant at higher than lower elevations, and we expected that the parasitoid would be more abundant at high-elevation. No clear trend was also found regarding host crop preference by $P$. scabriventris at lower elevations. This unexpected result could be owing to the short-term observation period, i.e., one to two years after release; in the long run, $P$. scabriventris may become more abundant at high-elevation, at least reaching the same levels as currently observed at lower elevations. According to various authors, the sex ratio of $P$. scabriventris at higher temperatures is more female-biased and its life cycle is shorter than at low temperatures (Mujica et al. 2009, Chabi-Olaye et al. 2013, Akutse et al. 2015, Foba et al. 2015b). The femalebiased sex ratios coupled with shorter life cycle may have led to the faster establishment and better performance of $P$. scabriventris at the low-elevation.

The indigenous solitary larval-pupal endoparasitoid O. dissitus was the third most abundant parasitoid species across all elevations in this study. Abundance of and parasitism by this parasitoid followed similar trend to that observed for P. scabriventris, with a higher parasitism rate at low-elevation compared with mid- and high-elevations. This observation fits the findings of Bordat et al. (1995), who predicted that O. dissitus would perform better between 20 and $25^{\circ} \mathrm{C}$. However, Li et al. (2012) reported higher performance of $\mathrm{O}$. dissitus in South Florida during cooler conditions of temperature between 15 and $20^{\circ} \mathrm{C}$, like that of $P$. scabriventris. According to Foba et al. (2015), leafminers are more abundant at high than lower elevations, and we expected that the parasitoid would be more abundant at high-elevation. In addition, no clear trend was found regarding host crop preference by $O$. dissitus at lower-elevation. All 20 crops surveyed were host to at least one of the nine parasitoid species recovered; with $D$. isaea being the most frequently recovered (19 crops), while P. scabriventris and O. dissitus were reared from 18 crops each. Chabi-Olaye et al. (2008) also reported a high diversity in host range for the indigenous leafminer parasitoids in Kenya. Although leafminer parasitoids are known to be generalists attacking several leafminer species on different host crops (Serantes de González 1974, Valladares and Salvo 2001, Videla et al. 2006, Valencia 2008, Chabi-Olaye et al. 2013), clear preferences of these parasitoids based on host crops and location have been observed (Zehnder and Trumble 1984, Johnson and Hara 1987, Schuster et al. 1991, Salvo and Valladares 1997, Murphy and Lasalle 1999, Tran et al. 2006, Rauf et al. 2000). In this study, the Fabaceae, especially beans, and the Solanaceae, especially tomato, were the most important hosts on which the highest total parasitoids were recovered. Other field-based studies have also demonstrated that the Fabaceae are the most suitable hosts for Liriomyza species and their natural enemies (Tokumaru and Abe 2005, Tran et al. 2007, Chabi-Olaye et al. 2008, Mujica and Kroschel 2011, Okoth et al. 2014, Foba et al. 2015a). Finidori-Logli et al. (1996) and Wei and Kang (2006) have shown that female D. isaea and O. dissitus, respectively, were strongly attracted to the odors arising from Liriomyza-infested bean plants. Among the frequently surveyed host crops, snow pea, sugar snap, and potato were found only at the high-elevation. Okra was surveyed only at low-elevation. French bean was found at both high- and mid-elevations and was highest at 
the later elevation. Tomato and local kidney bean were grown at all the elevations, with the former crop being frequently surveyed at low-elevation, followed by mid-elevation, and then high-elevation, whereas the latter was frequently surveyed at mid-elevation, followed by low-elevation, and then high-elevation.

Further studies are recommended to assess possible change in parasitism rates and the relative contribution of different parasitoid species to leafminer parasitism, as well as the spread of newly introduced species. These parasitoids may offer viable alternatives to the application of insecticides or at least reduce their application frequency.

\section{Acknowledgments}

We thank Dr. A. Gumovsky from the Royal Museum of Central Africa, Belgium, for assisting in the identification of leafminer parasitoids. We also thank the numerous farmers who warmly received us and gladly allowed us to collect leafminer flies-infested leaves from their fields. The study was conducted with the financial support from the Federal Ministry for Economic Cooperation and Development, Germany (BMZ), through the German Federal Enterprise for International Cooperation (GIZ; Grant number: 09.7860.1-001.00; Contract number: 81121261). The first author received a scholarship from the German Academic Exchange Service (DAAD) through the African Regional Postgraduate Programme in Insect Science (ARPPIS) at the International Center of Insect Physiology and Ecology (ICIPE), Nairobi, Kenya.

\section{References Cited}

Akutse, K. S., J. Van den Berg, N. K. Maniania, K. K. M. Fiaboe, and S. Ekesi. 2015. Interactions between Phaedrotoma scabriventris Nixon (Hymenoptera: Braconidae) and Diglyphus isaea Walker (Hymenoptera: Eulophidae), parasitoids of Liriomyza huidobrensis (Blanchard) (Diptera: Agromyzidae). Biol. Control 80: 8-13.

Andersen, A., E. Nordhus, V. T. Thang, T. T. T. An, H. Q. Hung, and T. Hofsvang. 2002. Polyphagous Liriomyza species (Diptera: Agromyzidae) in vegetables in Vietnam. Trop. Agric. (Trinidad). 79: 241-246.

Bates, D., M. Maechler, and B. Bolker. 2012. Ime4: Linear mixed-effects models using S4 classes.

Bazzocchi, G. G., A. Lanzoni, G. Burgio, and M. R. Fiacconi. 2003. Effects of temperature and host on the pre-imaginal development of the parasitoid Diglyphus isaea (Hymenoptera: Eulophidae). Biol. Control 26: 74-82.

Bordat, D., E. V. Coly, and P. Letourmy. 1995. Influence of temperature on Opius dissitus (Hym.: Braconidae), a parasitoid of Liriomyza trifolii (Dipt.: Agromyzidae). Entomophaga 40: 119-124.

Brehm, G., D. Süssenbach, and K. Fiedler. 2003. Unique elevational diversity patterns of geometrid moths in an Andean montane rainforest. Ecography 26: 456-466.

Costa-Lima, T. C., L. D. Geremias, and J. R. P. Parra. 2010. Reproductive Activity and Survivorship of Liriomyza sativae (Diptera: Agromyzidae) at different temperatures and relative humidity levels. Environ. Entomol. 39: 195-201.

Chabi-Olaye, A., N. Mujica, B. Löhr, and J. Kroschel. 2008. Role of agroecosystems in the abundance and diversity of Liriomyza leafmining flies and their natural enemies, pp. 6-12. In Proceedings, XXIII International Congress of Entomology, July 2008, Durban, South Africa.

Chabi-Olaye, A., N. M. Mwikya, and K. K. M. Fiaboe. 2013. Acceptability and suitability of three Liriomyza species as host for the endoparasitoid Phaedrotoma scabriventris: Implication for biological control of leafminers in the vegetable production system of Kenya. Biol. Control 65: 1-5.

Chaney, W. E. 1995. The pea leafminer as a pest of vegetable crops. Monterey Co. Extension Office. Crop Notes (October): 4.

Cheah, C. S. 1987. Temperature requirements of the chrysanthemum leafminer, Chromatomyla syngenesiae (Diptera: Agromyzidae), and its ectoparasitoid, Diglyphus isaea (Hym.: Eulophidae). Entomophaga 32: 357-365.
Foba, C. N., D. Salifu, Z. O. Lagat, L. M. Gitonga, K. S. Akutse, and K. K. M. Fiaboe. 2015a. Species composition, distribution, and seasonal abundance of Liriomyza leafminers (Diptera: Agromyzidae) under different vegetable production systems and agroecological zones in Kenya. Environ. Entomol. 1-10, (doi:10.1093/ee/nvu065).

Foba, C. N., Z. O. Lagat, L. M. Gitonga, K. S. Akutse, and K. K. M. Fiaboe. 2015b. Interaction between Phaedrotoma scabriventris Nixon and Opius dissitus Muesebeck (Hymenoptera: Braconidae): endoparasitoids of Liriomyza leafminer. Afr. Entomol. 23: 120-131.

Finidori-Logli, V., A. G. Bagnères, and J. L. Clément. 1996. Role of plant volatiles in the search for a host by parasitoid Diglyphus isaea (Hymenoptera: Eulophidae). J. Chem. Ecol. 22: 541-558.

Gao, Y., Z. Lei, Y. Abe, and S. R. Reitz. 2011. Species displacements are common to two invasive species of leafminer fly in China, Japan, and the United States. J. Econ. Entomol. 104: 1771-1773.

Gitonga, Z. M., A. Chabi-Olaye, D. Mithöfer, J. J. Okello, and C. N. Ritho. 2010. Control of invasive Liriomyza leafminer species and compliance with food safety standards by small scale snow pea farmers in Kenya. Crop Prot. 29: 1472-1477.

Guantai, M. M., C. P. K. O. Ogol, D. Salifu, J. M. Kasina, K. S. Akutse, and K. K. M. Fiaboe. 2015. Differential effects of pesticide applications on Liriomyza huidobrensis (Diptera: Agromyzidae) and its parasitoids on pea in Central Kenya. J. Econ. Entomol. 108: 662-671.

Haghani, M., Y. Fathipour, A. A. Talebi, and V. Baniameri. 2007. Temperature-dependent development of Diglyphus isaea (Hymenoptera: Eulophidae) on Liriomyza sativae (Diptera: Agromyzidae) on cucumber. J. Pest Sci. 80: 71-77.

Hassan, R. M. 1998. Maize technology development and transfer. A GIS application for research planning in Kenya. CAB International,Wallingford, United Kingdom.

Jaetzold, R., H. Schmidt, B. Hornetz, and C. Shisanya. 2006. Farm management handbook of Kenya Vol. II -Natural Conditions and Farm Management Information, 2nd Edition, Part B, Central Kenya. Subpart B2, Central Province.

Johansen, N. S., M. T. Tao, T. K. O. Le, and E. Nordhus. 2003. Susceptibility of Liriomyza sativae (Diptera: Agromyzidae) larvae to some insecticides scheduled for their control in North Vietnam. Grønn kunnskap. 7: $157-165$.

Johnson, M. W. 1993. Biological control of Liriomyza leafminers in the Pacific Basin. Micronesica Suppl. 4: 81-92.

Johnson, M. W., and A. H. Hara. 1987. Influence of host crop on parasitoids (Hymenoptera) of Liriomyza spp. (Diptera: Agromyzidae). Environ. Entomol. 16: 339-344.

Kang, L. 1996. Ecology and sustainable control of Liriomyza species. Science Press, Beijing.

(KEPHIS) Kenya Plant Health and Inspectorate Service. 2007. Strategic Corporate Business Plan (2007-2011). Kenya Plant Health and Inspectorate Service, Nairobi, Kenya.

Kessler, M., J. Kluge, A. Hemp, and R. Ohlemüller. 2011. A global comparative analysis of elevational species richness patterns of ferns. Glob. Ecol. Biogeogr. 20: 868-880.

Liu, W.-X., W.-X. Wang, W. Wang, Y.-B. Zhang, and F.-H. Wan. 2013. Characteristics and application of Diglyphus parasitoids (Hymenoptera: Eulophidae) in controlling the agromyzid leafminers. Acta Entomol. Sin. 56: $427-437$.

Li, J., D. R. Seal, G. L. Leibee, and O. E. Liburd. 2012. Seasonal Abundance and Spatial Distribution of the Leafminer, Liriomyza trifolii (Diptera: Agromyzidae), and its Parasitoid, Opius dissitus (Hymenoptera: Braconidae), on Bean in Southern Florida. Fla. Entomol. 95: 128-135.

Malais, M. H., and W. J. Ravensberg. 2003. Knowing and recognizing: The biology of glasshouse pests and their natural enemies, 2nd ed. Koppert BV. Reed Business Information, The Netherlands.

Malhi, Y., M. Silman, N. Salinas, M. Bush, P. Meir, and S. Saatchi. 2010. Introduction: elevation gradients in the tropics: Laboratories for ecosystem ecology and global change research. Glob. Change Biol. 16: 31713175 .

McCain, C. M. 2005. Elevational gradients in diversity of small mammals. Ecology 86: 366-372. 
Minkenberg, O. P. J. M. 1989. Temperature effects on the life history of the eulophid wasp Diglyphus isaea, an ectoparasitiod of leafminers (Liriomyza spp.), on tomatoes. Ann. Appl. Biol. 115: 381-397.

Mujica, N., and F. Cisneros. 1997. Developing IPM components for Leafminer Fly in the Cañete Valley of Peru, pp. 177-184. In: International Potato Center Program Report 1995-1996. CIP, Lima, Peru.

Mujica, N., and J. Kroschel. 2011. Leafminer fly (Diptera: Agromyzidae) occurrence, distribution and parasitoid associations in field and vegetable crops along the Peruvian coast. Environ. Entomol. 40: 217-230.

Mujica N., C. Valencia, L. Ramírez, C. Prudencio, and J. Kroschel. 2009. Temperature-dependent development of three parasitoids of the leafminer fly Liriomyza huidobrensis. In Proceedings of the 15th Triennial Symposium of the International Society for Tropical Root Crops. Lima, Peru 6th to 9th November 2009.

Murphy, S. T., and J. Lasalle. 1999. Balancing biological control strategies in the IPM of New World invasive Liriomyza leafminers in field vegetable crops. Biocontrol News Info. 20: 91-104.

Musundire, R., A. Chabi-Olaye, and B. L. K. Krüger. 2011. Diversity of Agromyzidae and associated hymenopteran parasitoid species in the afrotropical region: Implications for biological control. Biocontrol 56: 1-9.

Muylaert, K., K. Sabbe, and W. Vyverman. 2000. Spatial and temporal dynamics of phytoplankton communities in a freshwater tidal estuary (Schelde, Belgium). Estuar Coast Shelf S, 50: 673-687.

Noyes, J. 2003. Universal chalcidoidea database. (http://www.nhm.ac.uk/ento mology/chalcidoids/). (http://www.nhm.ac.uk/research-curation/research/ projects/chalcidoids/introduction.html)

Okoth, C. A., A. L. Deng, I. M. Tabu, K. S. Akutse, and K. K. M. Fiaboe. 2014. Effect of host plant on feeding, biological and morphological parameters of Liriomyza huidobrensis Blanchard (Diptera: Agromyzidae). Afr. Entomol. 22: 577-588.

Oksanen, J., G. F. Blanchet, R. Kindt, P. Legendre, P. R. Minchin, R. B. O’Hara, G. L. Simpson, P. Solymos, M. H. H. Stevens, and H. Wagner. 2015. Vegan: Community Ecology Package. R package version 2.3-0. (http://CRAN.R-project.org/package=vegan).

Parrella, M. P. 1987. Biology of Liriomyza. Ann. Rev. Entomol. 32: 201-224.

Pires-Venin, A. M. S. 2001. Identifying the components of ecological variation in a marine benthic megfauna. Rev. Bras. Oceanogr. 49: 29-38.

R Development Core Team. 2015. R: A language and environment for statistical computing. R Foundation for Statistical Computing, Vienna, Austria. (http://www.R-project.org/)

Rauf, A., B. M. Shepard, and M. W. Johnson. 2000. Leafminers in vegetables, ornamental plants and weeds in Indonesia: Surveys of host crops, species composition and parasitoids. Int. J. Pest Manage. 46: 257-266.

Salvo, A. 1996. Diversidad y estructura en comunidades de parasitoides (Hymenoptera) de minadores de hojas (Diptera: Agromyzidae), Ph. D. Tesis, Universidad Nacional de Córdoba, Argentina, p. 355.

Salvo, A., and G. Valladares. 1995. Complejo parasítico (Hymenoptera: Parasitica) de Liriomyza huidobrensis (Diptera: Agromyzidae) en haba. Agriscientia 12: 39-47.

Salvo, A., and G. Valladares. 1998. Taxonomic composition of hymenopteran parasitoid assemblages from Agromyzidae leaf-miners sampled in Central Argentina. Stud. Neotrop. Fauna Environ. 33: 116-123.

Salvo, A., and G. R. Valladares. 1997. An analysis of leaf-miner and plant host ranges of three Chrysocharis species (Hym.: Eulophidae) from Argentina. Entomophaga 42: 417-426.
Salvo, A., M. S. Fenoglio, and M. Videla. 2005. Parasitism of a leafminer in managed versus natural habitats. Agric. Ecosyst. Environ. 109: 213-220.

Serantes de González, H. 1974. Liriomyza huidobrensis (Blanchard, 1926) (Diptera: Agromyzidae). Rev. Soc. Entomol. Argent 34: 207-216.

Schuster, D. J., J. P. Gilreath, R. A. Wharton, and P. R. Seymour. 1991. Agromyzidae (Diptera) leafminers and their parasitoids in weeds associated with tomato in Florida. Environ. Entomol. 20: 720-723.

Spencer, K. A. 1985. East African Agromyzidae (Diptera): Further descriptions, revisionary notes and new records. J. Nat. Hist. 19: 969-1027.

Spencer, K .A. 1989. Leaf miners. In R. P. Kahn (ed.), Plant Protection and Quarantine, Vol. 2, Selected Pests and Pathogens of Quarantine Significance. CRC Press, Boca Raton, FL.

Tantowijoyo, W., and A. A. Hoffmann. 2010. Identifying factors determining the altitudinal distribution of the invasive pest leafminers Liriomyza huidobrensis and Liriomyza sativae. Entomol. Exp. Appl. 135: 141-153.

Tokumaru, S., and Y. Abe. 2005. Effects of host plants on the development and host preference of Liriomyza sativae, L. trifolii, and L. bryoniae (Diptera: Agromyzidae). Jpn. J. Appl. Entomol. Zool. 49: 135-142.

Tran, D. H., T.T.A. Tran, K. Konishi, and M. Takagi. 2006. Abundance of the parasitoid complex associated with Liriomyza spp. (Diptera: Agromyzidae) on vegetable crops in Central and Southern Vietnam. J. Fac. Agric., Kyushu Univ. 51: 115-120.

Tran, D. H., T.T.A. Tran, L. P. Mai, T. Ueno, and M. Takagi. 2007. Seasonal Abundance of Liriomyza sativae (Diptera: Agromyzidae) and its Parasitoids on Vegetables in Southern Vietnam. J. Fac. Agric., Kyushu Univ. 52: 49-55.

Valencia, C. 2008. Life cycle studies for the Braconidae Phaedrotoma scabriventris, an important endoparasitoid of Liriomyza huidobrensis in the highlands of Peru. Undergraduate thesis, UNALM, Lima, Peru, p. 121.

Valladares, G., and A. Salvo. 2001. Community dynamics of leafminers (Diptera: Agromyzidae) and their parasitoids (Hymenoptera) in a natural habitat from Central Argentina. Acta Oecologica 22: 301-309.

van Der Linden, A. 2004. Biological control of leafminers on vegetable crops, pp. 235-251. In K. Heinz, R. van Driesche, and M. Parrella (eds.), Biocontrol in Protected Culture. Ball Publishing, Batavia, Illinois.

Videla, M., G. Valladares, and A. Salvo. 2006. A tritrophic analysis of host preference and performance in a polyphagous leafminer. Entomol. Exp. Appl. 121: 105-114.

Waterhouse, D. F., and K. R. Norris. 1987. Liriomyza species (Diptera: Agromyzidae) leafminers, pp. 159-176. In D. F. Waterhouse and K. R. Norris (eds.), Biol. Control.: Pacific prospects. Inkata Press, Melbourne, Australia.

Weintraub, P. G. 2001. Changes in the dynamics of the leafminer, Liriomyza huidobrensis in Israeli potato fields. Int. J. Pest Manage. 47: 95-102.

Weintraub, P. G., and A. R. Horowitz. 1995. The newest leafminer pest in Israel, Liriomyza huidobrensis. Phytoparasitica 23: 177-184.

Wei, J. N., and L. Kang. 2006. Electrophysiological and behavioural responses of a parasitic wasp to plant volatiles induced by two leafminer species. Chem. Senses 31: 467-477.

Yıldırım, E. M., and A. Ünay. 2011. Effects of different fertilizations on Liriomyza trifolii (Burgess) (Diptera: Agromyzidae) in tomato. Afr. J. Agric. Res. 6: 4104-4107.

Zehnder, G. W., and J. T. Trumble. 1984. Host selection of Liriomyza species (Diptera: Agromyzidea) and associated parasitoids in adjacent plantings of tomato and celery. Environ. Entomol. 13: 492-496. 